\title{
Holoprosencephaly with agenesia of the prosencephalic ventricle
}

\author{
Milena Laure-Kamionowska1 ${ }^{1}$, Krystyna Szymanska ${ }^{1,2}$, Teresa Klepacka ${ }^{3}$ \\ ${ }^{1}$ Department of Experimental and Clinical Neuropathology, Mossakowski Medical Research Centre, Polish Academy of Sciences, \\ Warsaw, ${ }^{2}$ Department of Child Psychiatry, Medical University of Warsaw, ${ }^{3}$ Department of Pathomorphology, Institute of Mother \\ and Child, Warsaw, Poland
}

\begin{abstract}
Malformations of the forebrain are characterized by abnormalities in size, shape, and arrangement of the cerebral hemispheres and ventricles. We present the morphological picture of a brain with failure of the forebrain complementary to holoprosencephaly coexisting with absence of the anterodorsal part of the prosencephalic ventricles. The anomaly can be graded within the holoprosencephalic spectrum due to the main morphological features. However, such alterations as aplasia of the forebrain ventricles and prominent leptomeningeal gliomesodermal proliferation are related to atelencephaly. The observations confirm the common pathogenic mechanism of aprosencephaly/ atelencephaly and holoprosencephaly. The malformation corresponds to a wide continuous spectrum with no clearcut boundaries of abnormal formation of the prosencephalon.
\end{abstract}

Key words: holoprosencephaly, aprosencephaly, atelencephaly, aventriculi, aplasia of the prosencephalic ventricle

\section{Introduction}

Prosencephalon is the primordial forebrain vesicle at the cephalic part of the neural tube following closure of the anterior neuropore. During the next developmental steps the cerebral hemispheres and diencephalon will be formed. Abnormal ventral induction may result in disorders of formation, cleavage and midline development of prosencephalic structures [22,30]. Malformations of the forebrain are characterized by abnormalities in size, shape, and arrangement of the cerebral hemispheres and ventricles. Developmental failure characterized by deficient midline division of the forebrain into two hemispheres with accompanying midline defects results in holoprosencephaly (HPE). The main features are characterized by the variable loss of midline structures of the brain and face, as well as fusion of the cerebral hemispheres into the holosphere and the lateral ventricles into a single midline monoventricle. The monoventricle spreads anteriorly as a crescent-shaped cavity and divides posteriorly into temporal horns [22]. A few cases with partial or completely missing ventricular lumina in holoprosencephalic brains have been described [7,12,25]. Diagnosis of absence of supratentorial ventricles was based on neuroimaging analysis. Cerebral ventricles were not identifiable in ultrasound and magnetic resonance imaging scans. 
We had the opportunity to describe the morphological picture of a brain with failure of the forebrain and agenesia of the anterodorsal part of the prosencephalic ventricles.

\section{Case description}

The premature female infant was born by cesarean section because of labor in progress at the $32^{\text {nd }}$ week of gestation. It was a twin pregnancy; the baby was born second. The 21-year-old mother was in her first pregnancy. The birth weight of the newborn was $840 \mathrm{~g}$ (1 percentile), length $38 \mathrm{~cm}$, crown-rump length $22 \mathrm{~cm}$, head circumference $19 \mathrm{~cm}$, chest circumference $20 \mathrm{~cm}$. Apgar score was 1.2 after 1 and 5 minutes. The child presented craniofacial abnormalities: cyclopia, nasal hypoplasia, cleft palate, failure of the forehead. The girl died after one hour. The first born twin is alive.

Postmortem examination revealed abnormal features of the face - small flattened nose, single nostril, two palpebral fissures, the right completely sealed, right eyeball impalpable. In the lungs severe alveolar emphysema, hyperemia and disseminated coagulation in small capillaries were noted. The internal organs did not present malformations.

Neuropathological examination: Macroscopically the formalin-fixed brain weighed $29 \mathrm{~g}$ (below 1 percentile). The front part of the brain was abnormal in size and shape. The telencephalon was small, undivided, disc shaped, situated in front of the cerebellum instead of overlaying it. The interhemispheric fissure was absent. The convolutional pattern of the holosphere was aberrant, and the cerebral lobes were not defined. Cross-sections of this part revealed a C-shaped narrow solid mass. The ventricular cavity was not visible (Fig. 1).

The frontal part, in its rear portion, was connected with a short middle spherical shape structure comparable to the diencephalon (Fig. 1B). It was covered, particularly on its dorsal surface, by thick hypervascularized meninges. The picture may correspond to a collapsed dorsal sac cyst. Into this dorsal subarachnoid space an infundibulum-shaped orifice was opened. At this anatomical structure two mammillary bodies were well recognizable. The telencephalon-diencephalon junction was irregular and very small. Thin-walled vascular channels mixed with disorganized neural tissue closely adhered to the diencephalon at this level. At the diencephalic-mesencephalic junction cross-section, paired red nuclei were observed. The slit narrow third ventricle was observed at that level.

In the brainstem hypoplastic corticospinal tracts were observed. The cerebellum was relatively normal.

Microscopic examination was performed on paraffin-embedded slides stained with hematoxylineosin, cresyl violet, the Klüver-Barrera method, and immunohistochemically with glial fibrillary acidic protein (GFAP) and synaptophysin antibodies.

In the middle of the solid frontal mass, clusters of glial cells resembling subependymal glia and congested thin walled blood vessels were seen (Fig. 2). Single small ependymal rosettes and some thin channels composed of ependymal cells were arranged linearly mostly in the rear part (Fig. 3). Adjacent to them the germinative zone of small cells with hyperchromatic nuclei and scant cytoplasm was observed. Distribution of these cells was irregular. Neuroblasts were loosely dispersed without any specific arrangement or formed dense nodules depending on localization. White matter was narrow with an intense proliferation of fibrous astrocytes. A few mature disoriented neurons were misplaced in the white matter. The cerebral cortex band occupied the rim of the structure and presented a disturbed cortical pattern (Fig. 4). Cytoarchitecture of the cortex differed between the frontal and rear surface of the telencephalon. Layer I was hypocellular, while in the other superficial layers neurons were radially arranged in clusters. In layer $V$ multiple neuropil islands devoid of neurons were observed. The cortex of the rear telencephalic surface was more disorganized. The cortical band was thick with neurons concentrated in the deepest layers. In the superficial layers only a few small islands of neurons were seen. The cortical architectonic of inferior-medial gyri resembled dysplastic hippocampal and entorhinal cortex. Striatum was indiscernible.

Beneath the telencephalon dorsal diencephalon was covered by gliomesenchymal membranes with ependymal cells and choroid plexus elements consistent with the appearance of the dorsal sac membrane. Cell-rich mesenchymal and glial tissue with angiomatous cavernoma-like structures and multiple congested vessels surrounded the ventral diencephalon. The structures of the diencephalon were rudimentary. An indistinct fused mass and indiscernible anatomical nuclei were observed. The third ventricle appeared in the lowest midline part of the diencephalon, close to the diencephalon-mesencephalon 

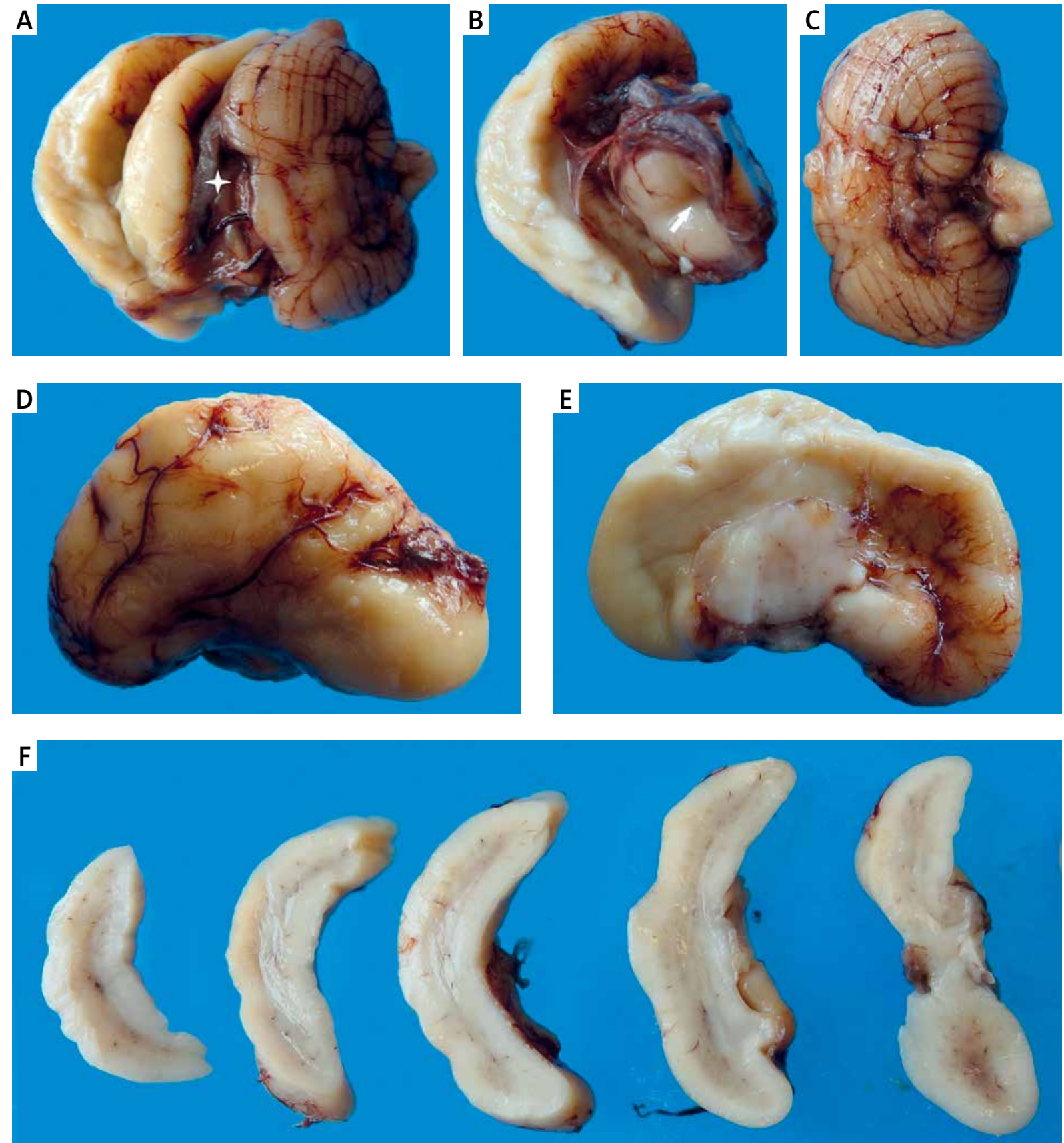

Fig. 1. Macroscopic view of the malformed brain. A) Dorsal view of the whole brain, collapsed dorsal cyst (asterisk). B) Undivided telencephalon and diencephalon, infundibulum-shaped orifice opened to the subarachnoid space (arrow). C) The well-formed cerebellum, development compatible with gestational age. D) Continuous across the midline telencephalon with aberrant convolutional pattern; there is no interhemispheric fissure-frontal view. E) Telencephalon, view from the back on the telencephalon-diencephalon junction. F) Cross-section through telencephalon, C-shaped narrow solid mass without recognizable ventricle. 

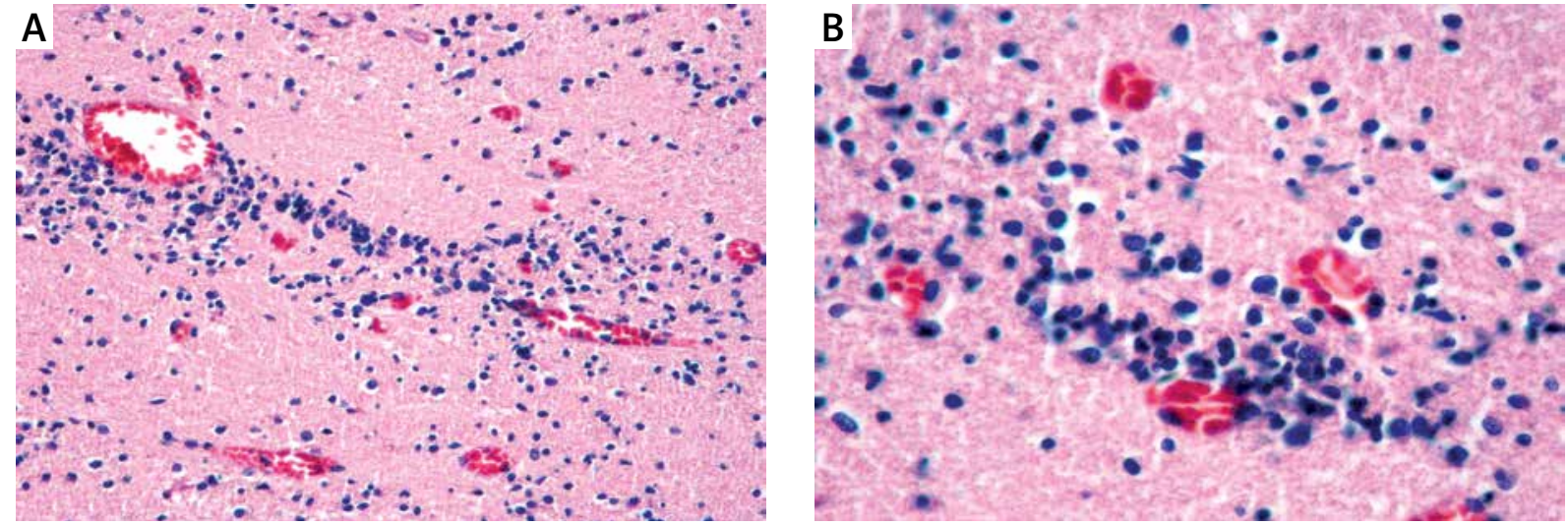

Fig. 2. Aligned glial cells resembling subependymal glia and congested thin-walled blood vessels located in the middle of the solid frontal mass. Hematoxylin-eosin. A) Magn. $\times 200$; B) magn. $\times 400$.

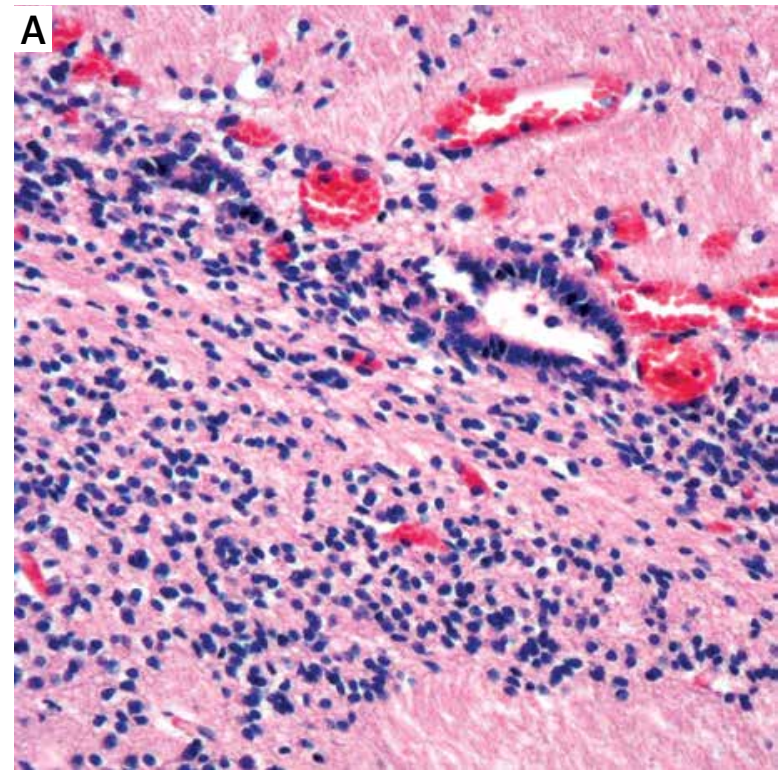

junction. The aqueduct was narrow, and the $4^{\text {th }}$ ventricle was normal. The pons, medulla oblongata and cerebellum were properly developed.

\section{Discussion}

Severe brain malformations may present a wide spectrum of variants. Difficulties in classification require detailed analysis of their morphological picture with regard to normal development of the central nervous system.

During embryological development the prosencephalon is the primitive forebrain vesicle at the rostral end of the neural tube following closure of the anterior neuropore [18]. The lamina terminalis is the membrane that closes the anterior neuropore.

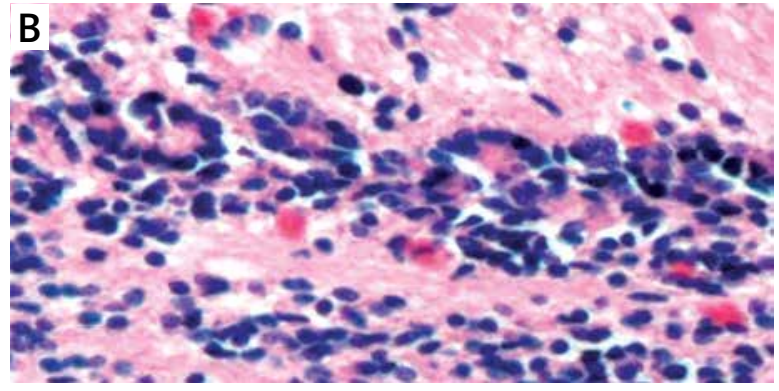

Fig. 3. Aplastic ventricle replaced by a few rosettes and thin small channels composed of ependymal cells. Hematoxylin-eosin. A) Magn. ×200; B) magn. $\times 400$.

An intact notochord is important for the induction of lamina terminalis. The prosencephalon develops around the lamina terminalis [24]. The primordial ventricular system originates also at the time of neural tube closure. The wall of the forebrain vesicle is composed by the neuroepithelium around the primordial ventricle. All forebrain structures begin their development in the zone around the ventricles. Neuronal migration is the way by which neurons travel from their origin to their final position in the brain. At 33 gestational days the first wave of neuroblasts migrates radially from the periventricular zone to the pial surface. The prosencephalon gives rise to the telencephalon and diencephalon. The telencephalon and diencephalon are formed from the fore- 


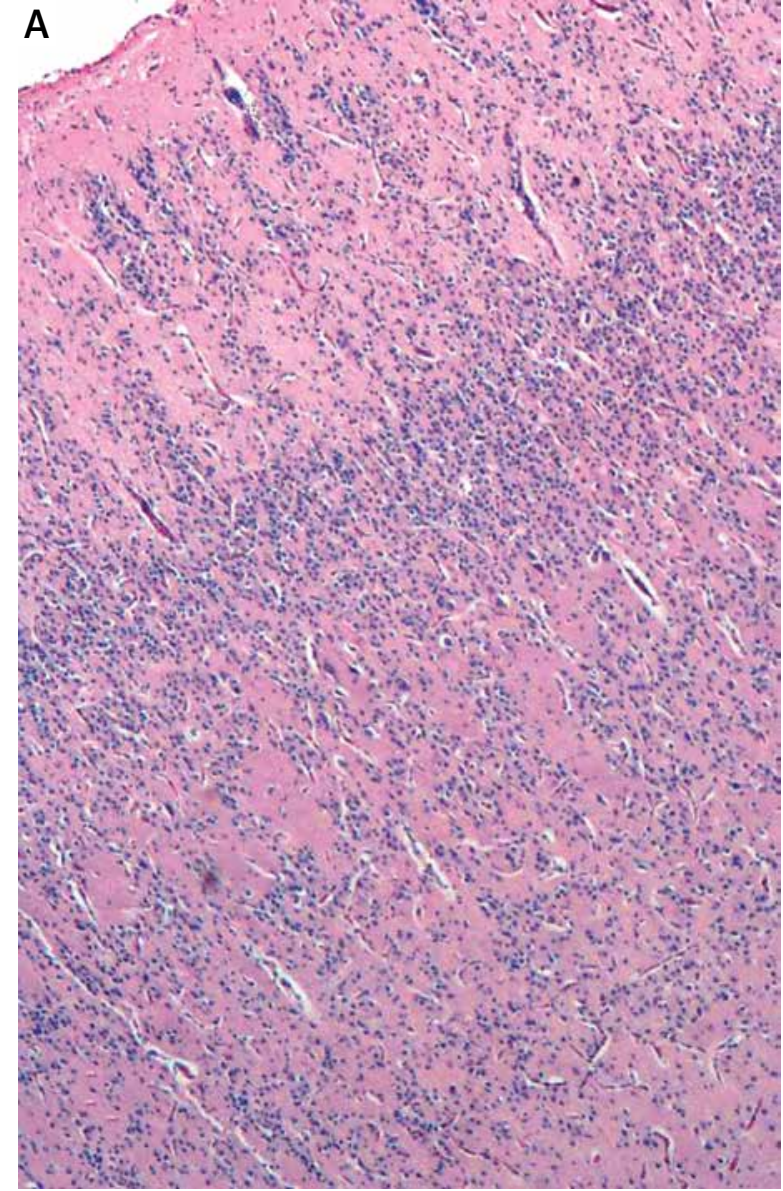

Fig. 4. Cytoarchitecture of the cerebral cortex. A-B) Frontal surface of the forebrain. Hypocellular layer I, radially arranged clusters of neurons in the superficial layers, neuropil islands in layer V. C) Disorganized cortex at rear surface of telencephalon. Thick cortical band with neurons concentrated in the deepest layers. In the superficial layers only a few small islands of neurons. Cresyl violet. Magn. $\times 100$.
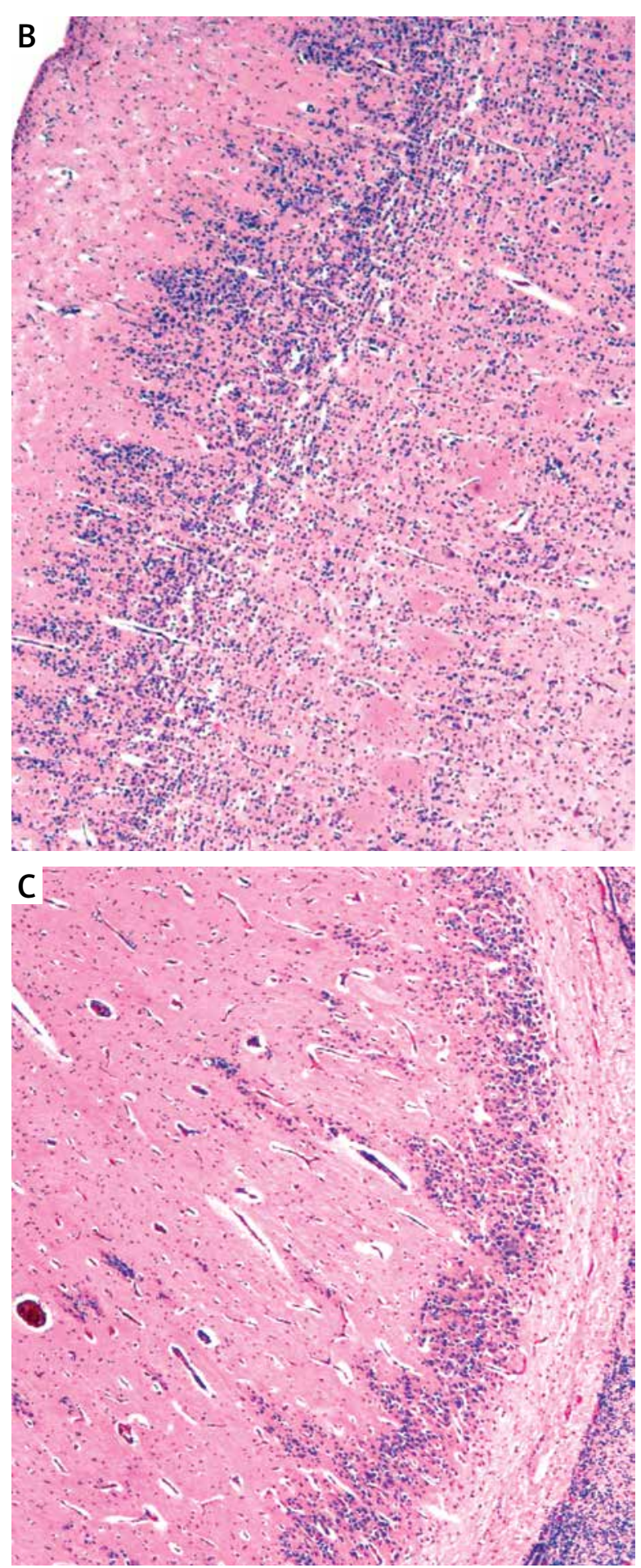

internal arrangement of the forebrain and its cavities. The dorsal and lateral growth of the neopallium forms the parietal and frontal lobes, and the posterior and ventral expansions form the occipital and temporal lobes. Following dynamic backwards 
expansion the hemispheres cover the thalami by $3^{\text {rd }}$ month, by the $4^{\text {th }}$ the midbrain, and by the $6^{\text {th }}$ gestational month the occipital lobes begin to cover the cerebellum. In the meantime the hypothalamus, thalamus and basal ganglia differentiate and settle in their normal anatomical localization. Simultaneously the cavities corresponding to the lateral ventricles enlarge backwards and downwards, forming the occipital and temporal horns, and the anterior horns and bodies become compressed by the expanding basal ganglia and callosal body $[13,17,22,24]$.

The morphogenetic steps are controlled and coordinated by signaling pathways such as Sonic hedgehog, bone morphogenetic protein, fibroblast growth factor, and nodal signaling [21]. Nodal signaling is essential for the initial specification of the prechordal plate, hedgehog signaling is crucial for the ventral forebrain development, retinoid signaling is critical in anterior-posterior patterning, fibroblast growth factor signaling is pivotal in growth of the developing forebrain due to cell proliferation and midline formation, and bone morphogenetic protein signaling participates in the organization of the medial-lateral axis of the developing telencephalon and is necessary for formation of the dorsal midline $[21,26]$. Mutations in these pathways have been determined in human patients and animal models of holoprosencephaly $[1,3-5,15,17]$. Polygenic mechanisms and gene-environmental interactions play a major role in the formation of holoprosencephaly [27].

Holoprosencephaly is a developmental failure of the forebrain characterized by its faulty midline division with concomitant associated midline defects [8]. Defect of neural induction at the lamina terminalis and inappropriate patterning of the rostral neural tube into the prosencephalon with a significant role of the prechordal plate play crucial roles $[18,23]$.The prosencephalon fails to divide sagittally into the cerebral hemispheres, transversely into the telencephalon and diencephalon, and horizontally into the olfactory tracts and bulbs [3]. An abnormally small prosencephalic protrusion with a single ventricle was observed early during embryogenesis [26,31]. A critical period for holoprosencephaly occurs prior to neural tube closure, about the gastrulation or primitive streak stage, around the sixteenth day after fertilization. Perturbation of gene expression at this stage can disturb later development of the forebrain and result in holoprosencephaly-like malformations.
The presented case demonstrated characteristic features of classical holoprosencephaly [14]. The brain was evidently hypoplastic, with a very small, undivided, disc-shaped telencephalon without an interhemispheric fissure. The cerebral lobes could not be defined. The gyral pattern was abnormal. The frontal part was small and did not cover the midbrain.

The middle part of the brain corresponding to the diencephalon was covered in its dorsal part by meninges forming the dorsal cyst. Into this subarachnoid space the infundibulum of the third ventricle opened. A common feature in holoprosencephaly is the presence of a dorsal sac membrane, which represents the unfolded diencephalic roof plate and covers the dorsocaudal part of the prosencephalic ventricle [22,29]. Simon [28] suggested that the unseparated thalamus in holoprosencephaly blocks the way out for cerebrospinal fluid leakage from the third ventricle, resulting in expansion of the posterodorsal portion of the ventricle to form the cyst. Probst and Sarnat combined the origin of the dorsal cyst with the dilated suprapineal recess of the third ventricle [22,23]. The roof plate, which forms at the dorsal midline of the neural tube, is a well-known signaling center in central nervous system (CNS) development. Multiple developmental processes in the dorsal telencephalon depend on the roof plate. The roof plate is essential for normal external cortical mantle formation and dorsal cortical patterning. Bone morphogenetic protein signaling plays a role in the roof plate patterning functions [2]. Roof plate cell loss causes reduction of the Bmp activity gradient and failed midline induction.

On coronal sections through the front part of the brain the lack of a ventricular cavity drew attention. Instead of a single ventricular lumen there were only a few small ependymal rosettes and thin narrow channels lined with ependymal cells. It is difficult to comment on whether the prosencephalic part of the ventricular system developed primarily or was secondarily obliterated. During the normal development of the ventricular system there are transient fetal ventricular protrusions into olfactory bulbs and into centers of the optic nerves. These sacs lined with ependyma become obliterated in early gestation [24].

The fetal ependyma matures in a precise temporal and spatial pattern in the human CNS [23]. In the vicinity of ependymal lined channels dispersed 
germinative small cells were seen. Disturbance in ependymal differentiation connected with the anomalous ventricle secondarily interferes with defective neuronal migration. Deficient neurogenesis and defective migration result in failure of neuroblasts to reach the surface and form a proper cortical plate. Some neurons lost their migratory way and settled in the white matter. White matter in the solid telencephalon was narrow with intensified gliosis, similar to that described in cases of classical holoprosencephaly $[11,14]$. The cerebral cortex band revealed cytoarchitecture characteristic for holoprosencephaly $[14,16]$. The segmentation of superficial neurons into irregular clusters and deeply placed glomerular islands devoid of nerves were observed in the dorsal surface of the telencephalon. The cortex of the ventral surface was severely disorganized.

The diencephalon presented an indistinct fused mass. Anatomical nuclei were indiscernible. Thick gliomesodermal tissue was attached to the diencephalon. Some variations in the severity of dysfunctions of the fused diencephalon and basal ganglia among the alobar HPE cases have been described in the literature [8]. Lack of separation of the thalamus in holoprosencephaly is thought to result from an imbalance of dorsal and ventral patterning signals in the embryonic forebrain - the cells that should occupy the midline of the prosencephalon never form, and the structures that should normally be lateral to the midline are fused [28].

The morphological picture of the presented brain can be properly graded within the holoprosencephalic spectrum. However, some elements matching other prosencephalic malformations occurred.

At the telencephalon-diencephalon junction a proliferation of thin-walled vascular channels mixed with disorganized neural tissue without recognizable structure corresponding to the "area cerebrovasculosa" was observed. The area cerebrovasculosa replaces the telencephalon of the anencephalic brain [24].

Anomalous ventricles correspond to aprosencephaly/atelencephaly (AP/AT). Aprosencephaly/atelencephaly is defined by the lack of prosencephalic derivatives $[3,9,10,14]$. An early failure of the neural tube in forming a normal prosencephalon plays a role in pathogenesis [30]. The failure occurs after neurulation and before the prosencephalon begins to grow [10]. In aprosencephaly both prosencephalic and diencephalic derivatives fail to develop. In atelencephaly the tiny forebrain remnant is composed of disorganized grey and white matter and prominent leptomeningeal gliomesodermal proliferation without a ventricular cavity. Ependymal lined tubules are observed. Complete absence of the cytoarchitecture of both the telencephalic and diencephalic structures is observed [24].

Pasquier [20] suggested a common pathogenic mechanism of aprosencephaly/atelencephaly and holoprosencephaly. Their neuropathological and mutational analysis with phenotype and genotype evaluation provides strong evidence for a link between AP/AT and holoprosencephaly and the role of the SIX3 gene in the genesis of AP/AT.

In summary, the presented malformation corresponds to a wide continuous spectrum with no clear-cut boundaries of abnormal formation of the prosencephalon. Disturbance in the sequence of interrelated and interdependent developmental pathways has influenced the abnormal course of forebrain formation. Failure in primary induction and improper patterning of the rostral neural tube during the early embryogenesis resulted in morphological alterations related to holoprosencephaly and atelencephaly. Coexistence of cerebral anomalies characteristic for holoprosencephaly and atelencephaly in the same case confirms the suggestion of a common pathogenic mechanism of these malformations.

\section{Disclosure}

Authors report no conflict of interest.

\section{References}

1. Bertrand N, Dahmane N. Sonic hedgehog signaling in forebrain development and its interactions with pathways that modify its effects. Trends Cell Biol 2007; 16: 597-605.

2. Cheng X, Hsu C, Currle S, Hu S, Barkovich AJ, Monuki ES. Central roles of the roof plate in telencephalic development and holoprosencephaly. J Neurosci 2006; 26: 7640-7649.

3. Cohen MM. Holoprosencephaly: Clinical, anatomic, and molecular dimensions. Birth Defects Res (Part A) 2006; 76: 658-673.

4. Cordero DR, Tapadia M, Helms JA. The etiopathologies of holoprosencephaly. Drug Discovery Today 2005; 2: 529-537.

5. Dubourg C, Bendavid C, Pasquier L, Henry K, Odent S, David V. Holoprosencephaly. Orphan J Rare Dis 2007; 2: 8.

6. Garfinkle WB. Aventriculy: a new entity? AJNR 1996; 17: 16491650.

7. Geng X, Oliver G. Pathogenesis of holoprosencephaly. J Clin Invest 2009; 119: 1403-1413.

8. Hayashi M, Araki S, Kumada S, Itoh M, Morimatsu Y, Matsuyama $\mathrm{H}$. Neuropathological evaluation of the diencephalon, 
basal ganglia and upper brainstem in alobar holoprosencephaly. Acta Neuropathol 2004; 107: 190-196.

9. Ippel PF, Breslau-Siderius EJ, Hack WWM, van der Blij HF, Bouve S, Bijlsma JB. Atelencephalic microcephaly: a case report and review of the literature. Eur J Pediatr 1998; 157: 493-497.

10. Kakita A, Hayashi S, Arakawa M, Takahashi H. Aprosencephaly: histopathological features of the rudimentary forebrain and retina. Acta Neuropathol 2001; 102: 110-116.

11. Kinsman SL. White matter imaging in holoprosencephaly in children. Curr Opin Neurol 2004; 17: 115-117.

12. Kumar S, Jaiswal JA, Rastogi M. Aventriculi associated with holoprosencephaly. J Clin Neurosci 2006; 13: 378-380.

13. Lowery LA, Sive H. Totally tubular: the mystery behind function and origin of the brain ventricular system. Bioessays 2009; 31 446-458.

14. Marcorelles P, Laquerriere A. Neuropathology of holoprosencephaly. Am J Med Genet Part C Semin Med Genet 2010; 154C: 109-119.

15. Mercier S, Duborg C, Belleguic M, Pasquier L, Loget P, Lucas J, Bendavid C, Odent S. Genetic counseling and "molecular" prenatal diagnosis of holoprosencephaly. Am J Med Genet Part C Semin Med Genet 2010; 154C: 191-196.

16. Mizuguchi M, Morimatsu Y. Histopatological study of alobar holoprosencephaly.1.Abnormal laminar architecture of the telencephalic cortex. Acta Neuropathol 1989; 78: 178-182.

17. Muenke M, Beachy PA. Genetics of ventral forebrain development and holoprosencephaly. Curr Opin Genet Dev 2000; 10 262-269.

18. Müller F, O’Rahilly R. Mediobasal prosencephalic defects, includ ing holoprosencephaly and cyclopia in relation to the development of the human forebrain. Am J Anat 1989; 185: 391-414.

19. O'Rahilly R, Müller F. The developmental anatomy and histology of the human central nervous system. In: Handbook of Clinical Neurology. Vol 6. Malformations. Myrianthopoulos NC (ed.). Elsevier Science Publishers, Amsterdam, New York 1987; pp. 1-17.

20. Pasquier L, Duborg C, Gonzales M, Lazaro L, David V, Odent S, Encha-Razavi F. First occurrence of aprosencephaly/atelencephaly and holoprosencephaly in a family with a SIX3 gene mutation and phenotype/genotype correlation in our series of SIX3 mutations. J Med Genet 2005; 42: e4.

21. Petryk A, Graf D, Marcucio R. Holoprosencephaly: signaling interactions between the brain and the face, the environment and the genes, and the phenotypic variability in animal models and humans. WIREs Dev Biol 2015; 4: 17-32.

22. Probst FP. The prosencephalies. Morphology, neuroradiological appearances and differential diagnosis. Springer-Verlag, Berlin, Heidelberg, New York 1979.

23. Sarnat HB, Flores-Sarnat L. Neuropathologic research strategies in holoprosencephaly. J Child Neurol 2001; 16: 918-931.

24. Sarnat HB. Disorders of the lamina terminalis:midline malformations of the brain. In: Cerebral dysgenesis. Embryology and clinical expression. Oxford University Press, New York 1992; pp. 167-207.

25. Sener RN. Aventriculi associated with holoprosencephaly. Comp Med Imaging Graph 1998; 22: 345-347.
26. Shiota K, Yamada S, Komada M, Ishibashi M. Embryogenesis of holoprosencephaly. Am J Med Genet Part A 2007; 143A: 30793087.

27. Shiota K, Yamada S. Early pathogenesis of holoprosencephaly. Am J Med Genet Part C Semin Med Genet 2010; 154C: 22-28.

28. Simon EM, Hevner RF, Pinter JD, Clegg NJ, Deglado M, Kinsman SL, Hahn JS, Barkovich AJ. The dorsal cyst in holoprosencephaly and the role of the thalamus in its formation. Neuroradiology 2001; 43: 787-791.

29. Utsunomiya H, Yamashita S, Takano K, Ueda Y, Fujii A. Midline cystic malformations of the brain: imaging diagnosis and classification based on embryologic analysis. Radiat Med 2006; 24: 471-481.

30. Volpe P, Campobasso G, De Robertis V, Rembouskos G. Disorders of prosencephalic development. Prenat Diagn 2009; 29: 340-354.

31. Yamada S. Embryonic holoprosencephaly: pathology and phenotypic variability. Congenit Anom 2006; 46: 164-171. 